\title{
Mechanism of the Color Reaction between $m$-Dinitrobenzene Derivatives and Alkali Cyanide. (I). Some Reaction Products of $m$-Dinitrobenzene with Potassium Cyanide (Organic Analysis. LXVIII ${ }^{1)}$ )
}

\author{
Tsutomu Momose, Yosuke Ohkura \\ and Junzo Shiota
}

Faculty of Pharmaceutical Sciences, Kyushu University2)

(Received April 22, 1968)

\begin{abstract}
Four reaction products produced in the color reaction of $m$-dinitrobenzene with potassium cyanide were separated by a chromatographic technique with alumina. Two of them were determined as 2-ethoxy-6-nitrobenzonitrile and 4,6-diethoxy-2,3-benzenedicarbonitrile respectively.

Remaining two substances were the main parts of the coloring matters, and their structures were presented as 2,3-dihydro-4-nitro-3-oxo-1H-indazole-7-carbonitrile or 2,3dihydro-6-nitro-3-oxo-1H-indazole-7-carbonitrile and 2,3-dihydro-6-nitro-3-oxo-1H-indazole-5-carbonitrile respectively. The reaction mechanism was also discussed.
\end{abstract}

$m$-Dinitrobenzene and its derivatives gave a brown red or dark violet coloration when heated in an alkali cyanide solution. This reaction was used in their detection ${ }^{3)}$ in the organic qualitative analysis. The structures of the main coloring matters produced in the reaction were supposed to be $m$-hydroxylaminocyanonitrobenzene derivatives from the result of a synthetic study on hydroxylaminonitrobenzenes. ${ }^{4}$

This supposition might be denied by the fact that the developed color of the reaction still remained unchanged even when a mineral acid was added in the reaction mixture. This paper describes the structures of some reaction products of $m$-dinitrobenzene with potassium cyanide, which are isolated from the reaction mixture in crystalline forms, and presents another mechanism of the color reaction.

\section{Isolation of the Reaction Products}

An ethanolic solution of $m$-dinitrobenzene was mixed with an aqueous solution of potassium cyanide, and heated at $70^{\circ}$ for appropriate time.

In the reaction, the molar ratio of potassium cyanide to $m$-dinitrobenzene, $5: 1$, was chosen for isolation of the coloring matters. The intensity of the developed color increased with the increasing concentration of potassium cyanide up to the ratio, 130:1, but a larger amount of resinous substance was formed and the separation of the coloring matters became more difficult.

The prolongation of the heating time and a higher temperature were also avoided to prevent coagulation of the coloring matters into clots.

The coloring matters produced on acidifying the reaction mixture with hydrochloric acid were extracted almost wholly with ethyl acetate. The dried extract on evaporating the solvent was dissolved in benzene. Chromatographic separation of the benzene solution on alumina gave five main fractions which were devided by their adsorption colors on alumina, and the resulting eluates were concentrated (Table I).

1) Part LXVII: T. Momose, Y. Ohkura, K. Matsunami and X. Arakawa, Rinshokensa, 11, 761 (1967).

2) Location: Katakasu Fukuoka.

3) V. Anger, Mikrochim. Acta, 2, 6 (1937).

4) W. Borche and E. Böcker, Chem. Ber., 37, 1844 (1904); L. Pfandler and A. Oppenheim, Z. Chem., $1,470(1865)$. 
TABLE I. Chromatographic Separation of the Reaction Products

\begin{tabular}{cll}
\hline $\begin{array}{c}\text { Fraction and } \\
\text { eluate No. }\end{array}$ & Color on alumina & Color of eluate \\
\hline 1 & slight yellow & almost colorless \\
2 & slight yellow & colorless \\
3 & orange & red \\
4 & violet & wine-red \\
5 & red violet & wine-red \\
\hline
\end{tabular}

Several other fractions were seen on the chromatogram, but they were so small and could not be treated successfully. The alumina column still adsorbed a large quantity of dark brown matter at the top, which could not be eluted with ethyl acetate or benzene.

The first and second eluates gave slight yellow leaflets of $\mathrm{mp} 136-137^{\circ}(\mathrm{I})$ in relatively high yield, and colorless needles of $\mathrm{mp} 212-213^{\circ}$ (II) respectively. The ethanolic solutions of I and II gave no coloration with sodium hydroxide or hydrochloric acid, suggesting that they were not the coloring matter in the reaction. From the third eluate, a small amount of orange needles of $\mathrm{mp} 183-184^{\circ}$ was obtained, but it was difficult to obtain the enough quantity to purify.

The largest eluate, the fourth, left dark violet needles with golden metallic luster of $\mathrm{mp} 215-216^{\circ}$ (decomp.) (III), and the fifth eluate gave violet prisms of $\mathrm{mp} 222-223^{\circ}$ (IV). III and IV had the absorption maxima at 580 and $540 \mathrm{~m} \mu$, respectively, when they were dissolved in an acetate-sodium hydroxide buffer solution of $\mathrm{pH} 13.2$ as shown in Fig. 1. On the other hand, the reaction mixture had a $\mathrm{pH}$ value of 13.2 , and showed an absorption shoulder around $550 \mathrm{~m} \mu$ (Fig. 1). Again, ethyl acetate solution of III and IV had the absorption

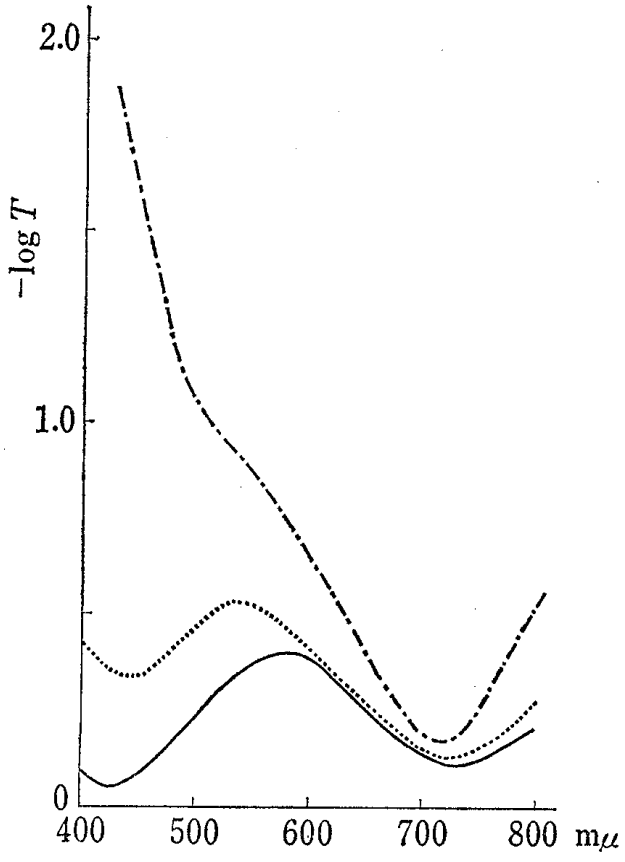

Fig. 1. Visible Absorption Spectra of III, IV and the Reaction Mixture, dissolved in Buffer Solution of $\mathrm{pH}$ 13.2

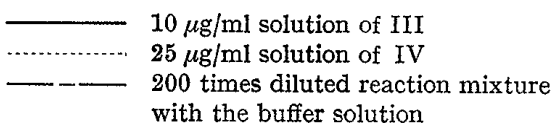

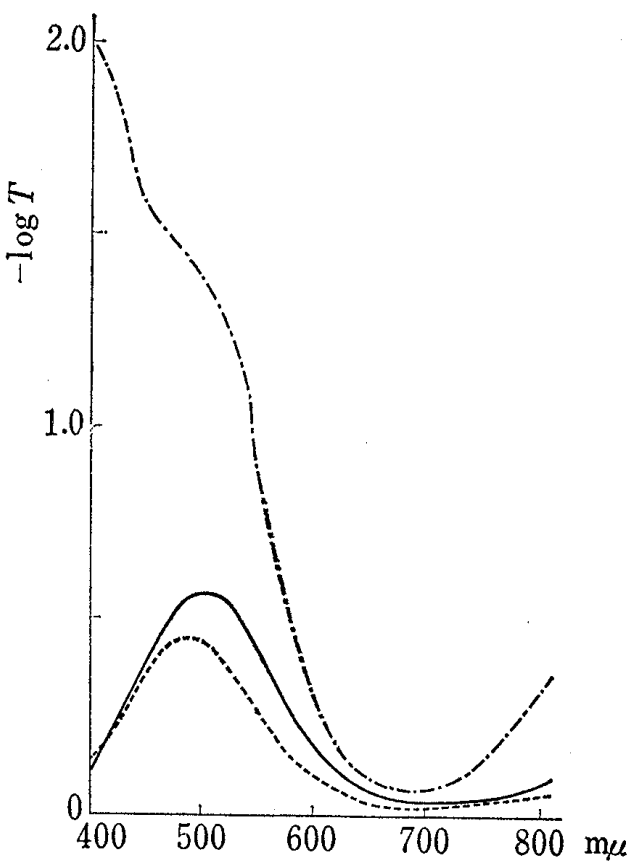

Fig. 2. Visible Absorption Spectra of Ethyl Acetate Solution of III, IV and Ethyl Acetate Extract of the Acidified Reaction Mixture

\footnotetext{
$25 \mu \mathrm{g} / \mathrm{ml}$ solution of III $25 \mu \mathrm{g} / \mathrm{ml}$ solution of IV AcOEt $(25 \mathrm{ml})$ extract of the acidified reaction mixture $(20 \mathrm{ml})$
} 
maxima at 500 and $485 \mathrm{~m} \mu$, respectively, and the ethyl acetate extract of the acidified reaction mixture had an absorption shoulder around $500 \mathrm{~m} \mu$ (Fig. 2). Those spectral data indicated that III and IV were the main parts of the coloring matters, and the others might exist in the top of alumina column, which might show the absorption maxima around $400-$ $450 \mathrm{~m} \mu$.

\section{Structures of the Reaction Products and Reaction Mechanism}

I was identified as 2-ethoxy-6-nitrobenzonitrile by the comparison of its physical properties with an authentic sample.5)

The data of elemental analysis of II and its molecular ion $\left(\mathrm{M}^{+}\right), m / e: 216$, in the mass spectrum (MS) agreed with the formula $\mathrm{C}_{12} \mathrm{H}_{12} \mathrm{O}_{2} \mathrm{~N}_{2}$. The infrared (IR) spectrum indicated that the compound had nitrile, ethoxy group and isolated aromatic hydrogen by their characteristic bands at $2240\left(v_{\mathrm{C} \equiv \mathrm{N}}\right), 2970-2860\left(v_{\mathrm{c}-\mathrm{H}}\right.$, alkyl $), 1222\left(v_{\mathrm{c}-0-\mathrm{c}}\right)$ and $845 \mathrm{~cm}^{-1}\left(\delta_{\mathrm{CH}}\right.$, out of plane) respectively. The nuclear magnetic resonance (NMR) spectrum had a triplet and a quartet due to ethyl protons at $1.52 \delta(6 \mathrm{H}, J=6.7 \mathrm{cps})$ and $4.13 \delta(4 \mathrm{H}, J=6.7 \mathrm{cps})$, suggesting that two ethoxy groups were in the molecule. Two singlets of uncoupled aromatic protons at $6.35 \delta(1 \mathrm{H})$ and $7.62 \delta(1 \mathrm{H})$ were also observed in the spectrum, and showed that two hydrogens were located at $p, p^{\prime}$-positions. Furthermore, the chemical shift of the former aromatic proton showed that two ethoxy groups were located at $o, o^{\prime}$-positions of the hydrogen. Therefore, II was characterized as 4,6-diethoxy-2,3-benzenedicarbonitrile.

From the data of elemental analysis of III and its $\mathrm{M}^{+}, m / e: 204$, in the MS, III was determined to have the formula $\mathrm{C}_{8} \mathrm{H}_{4} \mathrm{O}_{3} \mathrm{~N}_{4}$. Main fragment ions in the MS were observed at $m / e$ : $189\left(\mathrm{M}^{+}-\mathrm{NH}\right), 158\left(\mathrm{M}^{+}-\mathrm{NO}_{2}\right)$ and $130\left(\mathrm{M}^{+}-\mathrm{NO}_{2}-\mathrm{CO}\right)$.

The IR spectrum of III (Fig. 3,a) showed characteristic bands caused by aromatic amino, acid amide, nitrile, nitro and adjacent two aromatic hydrogens at $3440\left(v_{\mathrm{NH}}\right), 3255$ and 1655 $\left(v_{\mathrm{NH}}\right.$ and $\left.v_{\mathrm{C}=0}\right), 2240\left(v_{\mathrm{C} \equiv \mathrm{N}}\right), 1520$ and $1350\left(v_{\mathrm{NO}_{2}}\right)$, and $825 \mathrm{~cm}^{-1}\left(\delta_{\mathrm{CH}}\right.$, out of plane), respectively. The NMR spectrum of the compound was shown in Fig. 4, a, and had two doublet at $7.25 \delta$ $(1 \mathrm{H}, J=7.3 \mathrm{cps})$ and $7.75 \delta(1 \mathrm{H}, J=7.3 \mathrm{cps})$, which proved the existence of adjacent two aromatic hydrogens observed in the IR spectrum. A broad signal caused by aromatic imino proton at $8.25 \delta(1 \mathrm{H})$ was also observed in the spectrum. The existence of acid amide, which was suggested by the IR

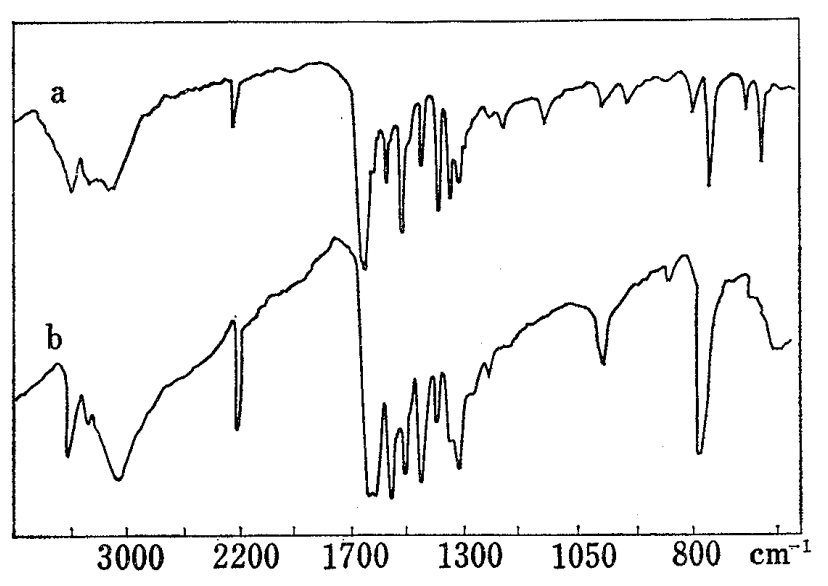

Fig. 3. Infrared Spectra of III and IV in KBr Pellet

$$
\text { a, III } b \text {, IV }
$$

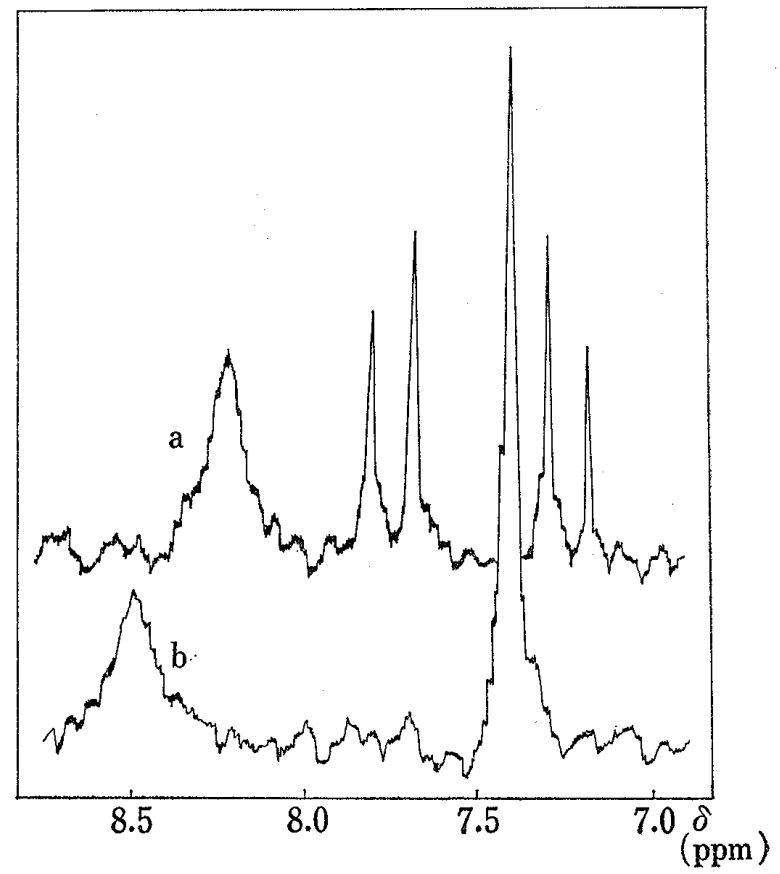

Fig. 4. NMR Spetra of III and $\mathrm{IV}$ in $\left(\mathrm{CD}_{3}\right)_{2} \mathrm{SO}$

$$
\text { a, III } \quad b, \text { IV }
$$

5) L. de.Bruyn, Rec. Trav. Chim., 2, 210 (1883). 
spectrum, was not confirmed from the NMR spectrum. This phenomenon might be explained by the fact that an amide proton usually gave a very broad and often undiscernible signal by the quadrupole relaxation of nitrogen nucleus. $\left.{ }^{6}\right)$

Acetylation of III gave a monoacetate as red brown needles mp $173^{\circ}$ (decomp.), which had an ester carbonyl band at $1760 \mathrm{~cm}^{-1}\left(v_{\mathrm{c}=0}\right)$ in the IR spectrum and a singlet due to acetyl protons at $2.15 \delta(3 \mathrm{H})$ in the NMR spectrum.

Above data indicated that III might be a tetrasubstituted benzene which had an imino, an acid imino, a nitrile and a nitro group in 1, 2, 3 and 4 positions of the ring. On the other hand, III was easily soluble in sodium hydroxide solution as an imidol anion, gave a color reaction with silver nitrate to form a violet and insoluble complex, and reduced an ammoniacal solution of silver nitrate. This behavior was very similar to that of 3 -indazolone derivative. ${ }^{7)}$ Therefore, the structure of the compound might be 2,3-dihydro-4-nitro-3-oxo-1H-indazole-7-carbonitrile<smiles>N#Cc1ccc([N+](=O)[O-])c2c(=O)[nH][nH]c12</smiles>

IIII<smiles>N#Cc1cccc2c(=O)[nH][nH]c12</smiles>

IIIb (IIIa) or 2,3-dihydro-6-nitro-3-oxo-1H-indazole-7-carbonitrile (IIIb).

The assumed structure might be confirmed by the fact that III gave 4-nitroanthranilic acid $\left.^{8}\right)$ when heated with sulfuric acid at high temperature. The resulting compound might be formed by the decarboxylation of 2-amino-4-nitro-isophthalic acid which was produced through the hydrolysis of cyano and acid imino groups of the molecule. The position of nitro group in the compound could not be determined successfully.

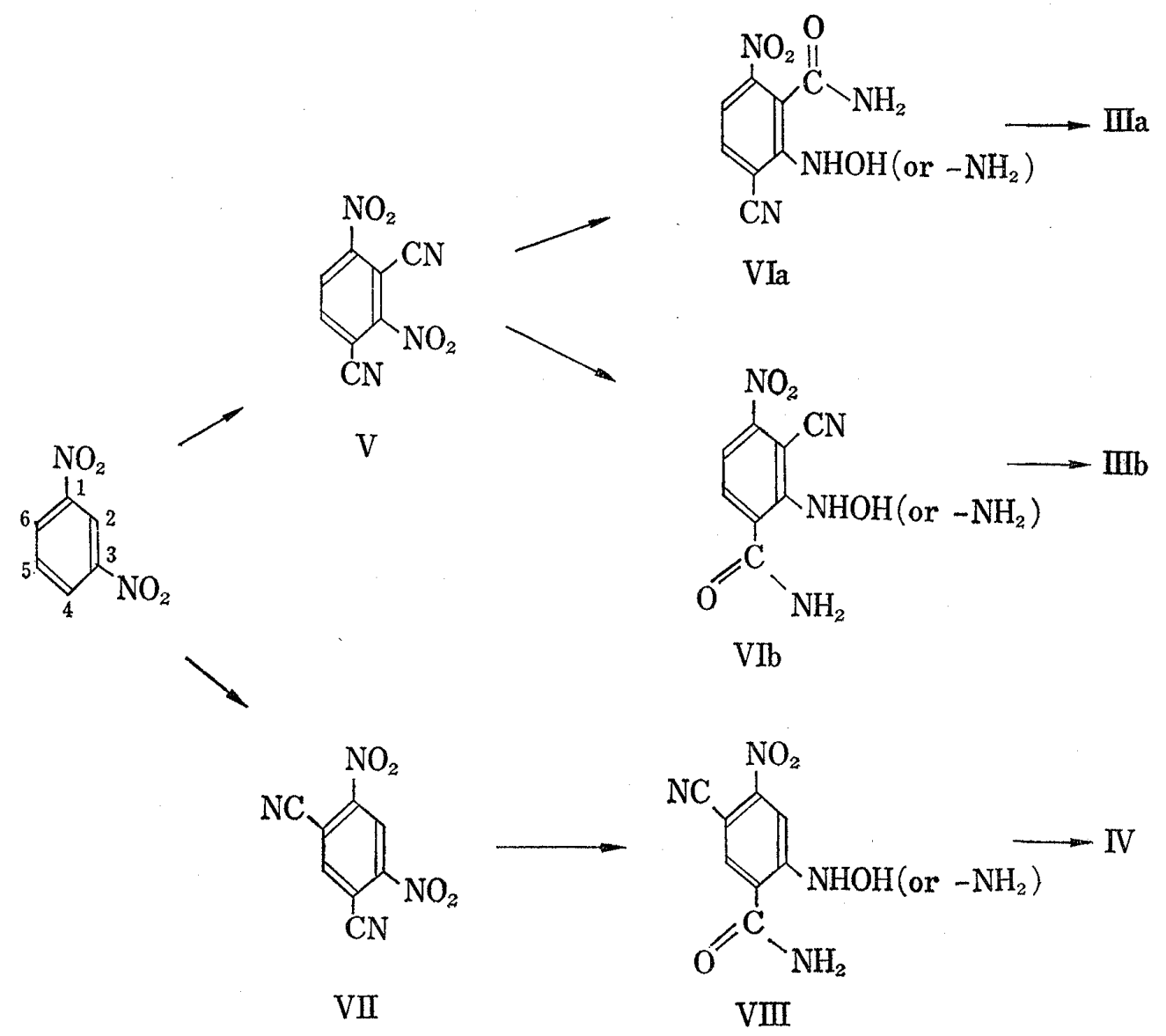

Chart 1. Schema of the Reaction Mechanism to form III and IV

6) D. Chapman, P.D. Magnus, "Introduction to Practical High Resolution Nuclear Magnetic Resonance Spectroscopy," Academic Press, London and New York, 1966, p.80.

7) K. Pfanstiel, J. Janecke, Chem. Ber., 75, 1096 (1942).

8) H.L. Wheeler, H.T. Barnes, Am. Chem. J., 20, 221, (1898). 
The data of the elemental analysis of IV, its $\mathrm{M}^{+}$and main fragment ions in the MS accorded with those of III, suggesting that IV might be an isomor of III. The IR spectrum of the compound partly resembled to that of III, and had absorption bands of aromatic amino, acid amide, nitrile, and nitro groups at $3390\left(v_{\mathrm{NH}}\right), 3220$ and $1640\left(v_{\mathrm{NH}}\right.$ and $\left.v_{\mathrm{C}=0}\right), 2240\left(v_{\mathrm{C}=\mathrm{N}}\right)$, and 1520 and $1330 \mathrm{~cm}^{-1}\left(\nu_{\mathrm{NO}_{2}}\right)$ respectively. While, it showed a characteristic band caused by isolated aromatic hydrogen at $835 \mathrm{~cm}^{-1}\left(\delta_{\mathrm{CH}}\right.$, out of plane) (Fig. $\left.3, \mathrm{~b}\right)$. The NMR spectrum of IV (Fig. 4, b) showed a broad signal of imino proton at $8.47 \delta(1 \mathrm{H})$ and a signal of uncoupled aromatic protons at $7.41 \delta(2 \mathrm{H})$ as signlet. The latter signal indicated that two hydrogens<smiles>N#Cc1cc(=O)[nH][nH]c1=O</smiles>
$\mathbb{N}$ were located at $p, p^{\prime}$-positions, and might cause a superposition of two "protons which had accidentally the same chemical shifts. A signal due to acid imide proton was not observed in the spectrum similarly as in the case of III. Furthermore, IV showed the same chemical behaviors as those of 3-indazolones. Therefore, the structure of IV might be 2,3dihydro-6-nitro-3-oxo- $1 \mathrm{H}$-indazole-5-carbonitrile (IV).

Now, the schema of mechanism to form III and IV in the color reaction might be written as shown in Chart 1. Two nitriles were first introduced in 2 and 4 , or 4 and 6 positions of $m$-dinitrobenzene $(\mathrm{V}, \mathrm{VII})$. The 2 or 4 positioned nitrile was then hydrolyzed to an acid amide under the alkaline condition of the reaction. The nitro group in the 3 position was reduced to hydroxylamino or amino group in the presence of excess potassium cyanide (VIa or VIb, VIII), which might combine with the amide by dehydration or oxidation to yield IIIa or IIIb and IV. This ring closure was also postulated in the formation of possible intermediates of the reaction of nitrobenzenes with potassium cyanide. ${ }^{9)}$

\section{Experimental ${ }^{10)}$}

Isolation of the Reaction Products-To a solution of $10 \mathrm{~g}$ of $m$-dinitrobenzene in $100 \mathrm{ml}$ of EtOH, $19.5 \mathrm{~g}$ of $\mathrm{KCN}$ dissolved in $200 \mathrm{ml}$ of $\mathrm{H}_{2} \mathrm{O}$ was added and heated at $70^{\circ}$ for $15 \mathrm{~min}$ with stirring. After cooling by adding ice-water, $30 \mathrm{ml}$ of conc. $\mathrm{HCl}$ was added, and $\mathrm{CO}_{2}$ gas was passed through the mixture for 20 min to remove $\mathrm{HCN}$.

The mixture was extracted with $300 \mathrm{ml}$ of AcOEt 2 times, and the combined extract was washed with $\mathrm{H}_{2} \mathrm{O}$, dried over $\mathrm{Na}_{2} \mathrm{SO}_{4}$, and concentrated to dryness in vacuo. The residue was dissolved in $800 \mathrm{ml}$ of benzene, passed through a short alumina column to remove resinous matter, and concentrated to $200-300 \mathrm{ml}$ in vacuo. The benzene solution was poured onto the column packed with $400 \mathrm{~g}$ of weakly acidic and moderately activated alumina, and eluted with benzene as shown in Table I. The solvent of each eluate was concentrated, and the separated crystals (I, II, III, IV and the crystals obtained from the 3rd eluate) were recrystallized from benzene respectively.

I - 2-Ethoxy-6-nitrobenzonitrile, ${ }^{5)}$ slight yellow leaflets, mp 136-137 , yield $300-400$ mg. No depression was observed on admixture with an authentic sample. Its IR and NMR spectra were identical with those of authentic sample. UV $\lambda_{\max }^{\mathrm{Acost}} \mathrm{m} \mu(\log \varepsilon): 261(3.73), 275(3.85), 335(3.68)$.

II Colorless needles, mp 212-213 , yield about $150 \mathrm{mg}$. Anal. Calcd. for $\mathrm{C}_{12} \mathrm{H}_{12} \mathrm{O}_{2} \mathrm{~N}_{2}: \mathrm{C}, 66.65$; $\mathrm{H}, 5.59 ; \mathrm{N}, 12.96$. Found: $\mathrm{C}, 66.70 ; \mathrm{H}, 5.48 ; \mathrm{N}, 12.96$. UV $\lambda_{\max }^{\mathrm{AeOEt}} \mathrm{m} \mu(\log \varepsilon): 262(4.09), 293(3.66), 298$ (3.64), $304(3.70)$.

III-Dark violet prisms, $\mathrm{mp} 215-216^{\circ}$ (decomp.), yield about $50 \mathrm{mg}$. Anal. Calcd. for $\mathrm{C}_{8} \mathrm{H}_{4} \mathrm{O}_{3} \mathrm{~N}_{4}$ : $\mathrm{C}, 47.07 ; \mathrm{H}, 1.98 ; \mathrm{N}, 27.45$. Found: $\mathrm{C}, 47.04 ; \mathrm{H}, 1.99 ; \mathrm{N}, 27.35$. UV $\lambda_{\max }^{\mathrm{Acost}} \mathrm{m} \mu(\log \varepsilon): 500(3.66), \lambda_{\mathrm{max}}^{\mathrm{HzO}}$ $(\mathrm{pH} 13.2) \mathrm{m} \mu(\log \varepsilon): 575$ (3.91).

Acetate of III-To a solution of $100 \mathrm{mg}$ of III in $3 \mathrm{ml}$ of pyridine, $2 \mathrm{ml}$ of $\mathrm{Ac}_{2} \mathrm{O}$ was added, and heated at $70^{\circ}$ for $5 \mathrm{~min}$. After cooling, $1 \mathrm{ml}$ of $\mathrm{H}_{2} \mathrm{O}$ was added, the mixture was allowed to stand $2-3 \mathrm{hr}$, and concentrated to dryness in vacuo. The separated crystals were recrystallized from ${ }^{*} \mathrm{H}_{2} \mathrm{O} 2$ times to red brown

9) E.F. Ullman, E.A. Bartkus, Chem. Ind. (London), 1962, 93; M. Rosenblum, J. Am. Chem. Soc., 82, 3796 (1960).

10) Absorption spectra were measured by a Shimadzu SV-50A Recording Spectrophotometer in a cell of $10 \mathrm{~mm}$ optical length. IR spectra were measured by a Koken DS-301 Infrared Spectrophotometer in $\mathrm{KBr}$ pellets. NMR spectra were determined with a Varian A-60 NMR Spectrometer at $60 \mathrm{Mc}$ in $\left(\mathrm{CD}_{3}\right)_{2} \mathrm{SO}$ using $\left(\mathrm{CH}_{3}\right)_{4} \mathrm{Si}$ as an internal standard. MS were measured by a Nihondenshi JMS-OlS Double Focusing Mass Spectrograph. 
needles, mp 17.2-173 (decomp.). Yield $60 \mathrm{mg}$. Anal. Calcd. for $\mathrm{C}_{10} \mathrm{H}_{6} \mathrm{O}_{4} \mathrm{~N}_{4}: \mathrm{C}, 48.79 ; \mathrm{H}, 2.46 ; \mathrm{N}, 22.76$. Found: C, 48.89; H, 2.61; N, 22.58.

4-Nitroanthranilic Acid from III- $100 \mathrm{mg}$ of III was dissolved in $75 \%(\mathrm{v} / \mathrm{v}) \mathrm{H}_{2} \mathrm{SO}_{4}$, and refluxed at $180^{\circ}$ for $3 \mathrm{hr}$. After cooling, the mixture was extracted with ether. The etherial layer was re-extracted with $5 \% \mathrm{Na}_{2} \mathrm{CO}_{3}$. The allaline layer was acidified with $10 \% \mathrm{HCl}$, extracted with ether, and the extract was washed with $\mathrm{H}_{2} \mathrm{O}$. After the evaporation of the solvent, the residue was recrystallized with $\mathrm{H}_{2} \mathrm{O}$ to orange yellow needles, $\mathrm{mp} 263^{\circ}$ (decomp.), yield $30 \mathrm{mg}$. No depression was observed on admixture with authentic 4-nitroanthranilic acid.8) Its IR spectrum was identical with that of an authentic sample.

IV_-dark violet prisms, mp 222-223 (decomp.), yield about $20 \mathrm{mg}$. Anal. Calcd. for $\mathrm{C}_{8} \mathrm{H}_{4} \mathrm{O}_{3} \mathrm{~N}_{4}$ :

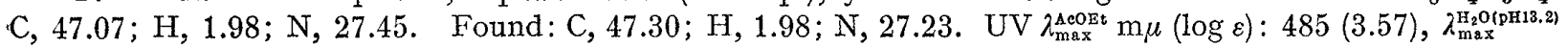
$\mathrm{m} \mu(\log \varepsilon): 530(3.64)$.

Acknowledgement The authors extend their gratitude to Mr. H. Matsui and Miss. Y. Soeda for absorption spectral measurements, and to Mr. M. Shido for elemental analysis. They are also indebted to Dr. H. Kobayashi for NMR spectral determinations and to the staff of Nihondenshi Co., Ltd. for mass spectral measurements. 